\title{
Analysis of Polycyclic Aromatic Hydrocarbons Using Desorption Atmospheric Pressure Chemical Ionization Coupled to a Portable Mass Spectrometer
}

\author{
Fred P. M. Jjunju, ${ }^{1}$ Simon Maher, ${ }^{1}$ Anyin Li, ${ }^{3}$ Abraham K. Badu-Tawiah, ${ }^{2}$ Stephen Taylor, ${ }^{1}$ \\ R. Graham Cooks ${ }^{3}$ \\ ${ }^{1}$ Department of Electrical Engineering and Electronics, University of Liverpool, Liverpool, L69 3GJ, UK \\ ${ }^{2}$ Department of Chemistry and Biochemistry, The Ohio State University, Columbus, OH 43210, USA \\ ${ }^{3}$ Chemistry Department, Purdue University, West Lafayette, IN 47907, USA
}

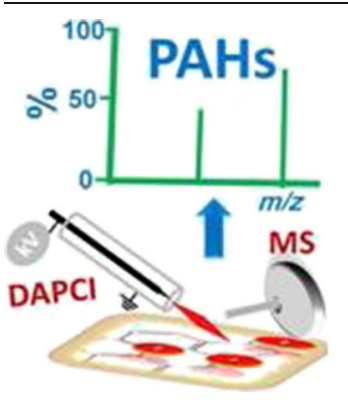

\begin{abstract}
Desorption atmospheric pressure chemical ionization (DAPCl) is implemented on a portable mass spectrometer and applied to the direct detection of polycyclic aromatic hydrocarbons (PAHs) and alkyl substituted benzenes. The presence of these compounds in the environment poses a significant threat to the health of both humans and wildlife because of their carcinogenic, toxic, and mutagenic properties. As such, instant detection outside of the laboratory is of particular importance to allow in-situ measurement at the source. Using a rapid, high throughput, miniature, handheld mass spectrometer, several alkyl substituted benzenes and PAHs (i.e., 1,2,3,5-tetramethylbenzene, pentamethylbenzene, hexamethylbenzene, fluoranthene, anthracene, benzo[ $k]$ fluoranthene, dibenz $[a, h]$ anthracene,
\end{abstract} acenaphthene, indeno[1,2,3-c,d]pyrene, 9-ethylfluorene, and 1-benzyl-3-methyl-naphthalene) were identified and characterized using tandem mass spectrometry (MS/MS) from ambient surfaces, in the open air. This method can provide almost instantaneous information while minimizing sample preparation, which is advantageous in terms of both cost and simplicity of analysis. This MS-based technique is applicable to a wide range of environmental organic molecules.

Keywords: Ambient ionization, Harsh environment chemical monitoring, PAHs, Alkylated benzenes, Portable MS, In situ analysis

Received: 19 September 2014/Revised: 10 October 2014/Accepted: 11 October 2014/Published online: 13 December 2014

\section{Introduction}

$\mathrm{T}$ he presence of polycyclic hydrocarbons (PAH) in our environment, even at low concentration, poses significant health hazards to humans and wildlife. The PAHs are known to be toxic [1], carcinogenic [2-4], as well as mutagenic [5]. Analytical methods that are capable of monitoring and identifying such hazardous compounds are, therefore, highly desirable $[6,7]$. Ex-situ methods based on solid-phase extraction [8,

Electronic supplementary material The online version of this article (doi:10.1007/s13361-014-1029-2) contains supplementary material, which is available to authorized users.

Correspondence to: Stephen Taylor; e-mail: S.Taylor@liv.ac.uk, R. Graham Cooks; e-mail: Cooks@purdue.edu
9] followed by gas chromatography (GC) or liquid chromatography (LC) mass spectrometry (MS) [10-14] are the most widely adopted methods for both quantitative and quantitative analysis of PAHs. Although, high sensitivity and specificity can be achieved using these GC/LC-MS-based methods, considerable time is required for sample pre-concentration and pretreatment; the sample must also be transported to the laboratory for analysis [15-18]. Ambient ionization methods [19-23] are well suited for portable mass spectrometers [24-27] as vacuum requirements are reduced. Moreover, the flexibility to use different ambient ionization sources allows a wide range of analytes to be measured in situ.

Ambient ionization MS is a technique in which ionization is performed directly on unmodified samples in air outside the vacuum, and is capable of providing instantaneous data while minimizing sample preparation [28]. In the past 10 years, 
several ambient ionization techniques have been exploited in the analysis of environmental organic molecules; most notably desorption electrospray ionization (DESI) [29, 30], direct analysis in real time (DART) [31, 32], low temperature plasma (LTP) [33, 34], and paper spray ionization [35-37]. Desorption atmospheric pressure chemical ionization (DAPCI) is a plasma-based ambient ionization source that is relatively underutilized compared with others [38]. DAPCI has been successfully utilized in the analysis of complex molecules [39], including melamine in powered milk [40], discerning between different variants of Chinese tea [41], analysis of fuels and petroleum oil mixtures [42], explosives, and narcotics [43].

Herein, we demonstrate that DAPCI coupled with a portable mass spectrometer is a suitable analytical method that can be used for "near-instant" in situ detection of polar alkylated benzenes and non-polar PAHs that are difficult to analyze [44]. In this work, we investigate the use of DAPCI for the detection of 1,2,3,5-tetramethylbenzene, pentamethylbenzene, hexamethylbenzene, fluoranthene, anthracene, benzo $[k]$ fluoranthene, dibenz $[a, h]$ anthracene, acenaphthene, indeno[1,2,3-c,d]pyrene, 9-ethylfluorene, and 1-benzyl-3methyl-naphthalene. We chose these alkylated benzenes and PAHs because they are known to possess carcinogenic and mutagenic properties [45]. Our results indicate that these hydrocarbons can be detected from ambient surfaces instantly. We also demonstrate that the structural characterization of these PAHs can be determined using tandem mass spectrometry (MS/MS) [46-49].

\section{Methods}

In a typical DAPCI MS experiment, a corona discharge is generated by applying a high DC voltage to a sharp needle and the reagent ions produced are directed pneumatically towards a surface using a carrier gas (e.g., nitrogen, helium). The analyte(s) is desorbed and ionized directly from the surface, presumably by a two-step mechanism involving thermal desorption followed by gas-phase ionization [38]. The DAPCI ion source was placed 1-5 $\mathrm{mm}$ in front of a mass spectrometer, while its electric potential was set to $+3 \mathrm{kV}$ and nitrogen was used as the carrier gas at a flow rate of $1 \mathrm{~L} / \mathrm{min}$. Approximately $\sim 3 \mathrm{ng} \mu \mathrm{L}^{-1}$ of each sample in methanol solvent $(100 \mathrm{ppm})$ was deposited on a filter paper surface and analyzed instantly without any sample preparation under a harsh environment.

\section{$D A P C I M S$}

The DAPCI system used in this work has been described previously [42]. It consists of a stainless steel needle with an elongated tapered tip, connected to a high voltage power supply (Figure 1). The elongated tip projects from a Teflon capillary tube carrying a high velocity flow of gas. The carrier gas is directed towards a substrate/surface to desorbs and ionize analyte(s), which may be present. The carrier gas used was nitrogen. The voltage applied to the electrode was typically $+3 \mathrm{kV}$ so as to produce a corona discharge in close proximity to the tip of the electrode. The source is optimally coupled to the atmospheric pressure inlet of the mass spectrometer placed at a distance of $2.5 \mathrm{~mm}$ [38].

\section{DAPCI MS Using a Miniature Mass Spectrometer}

A DAPCI ion source was interfaced to a miniature mass spectrometer (Mini 10), built and characterized at Purdue University (Figure 1). The mass analysis system, the vacuum system, the control system, and the detector are all integrated into a shoe box-sized aluminum box. The overall instrument uses $65 \mathrm{~W}$ average power and weighs $<10 \mathrm{~kg}$. The mass analyzer is a rectilinear ion trap (RIT) [50] operating at a frequency of $1 \mathrm{MHz}$ enclosed in a stainless steel manifold of $470 \mathrm{~cm}^{3}$ volume [51]. As a result of its simplified geometry and pressure tolerance, RITs have several advantages for miniaturization evidenced in previous applications [52]. The operating pressure was in the range $1 \times 10^{-5}$ Torr to ca. $5 \times 10^{-2}$ Torr, with mass analysis scans being performed in the lower pressure region $[53,54]$.

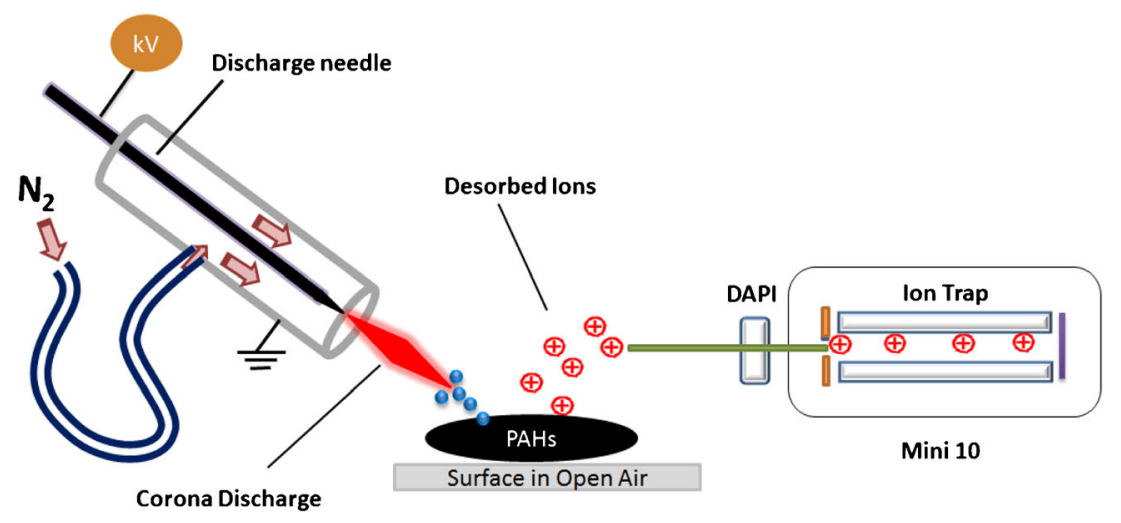

Figure 1. Desorption atmospheric pressure chemical ionization for direct analysis of PAHs using a miniature mass spectrometer (Mini 10) 


\section{Interface to the Mini 10 Mass Spectrometer}

To achieve an adequate vacuum, a discontinuous atmospheric pressure interface (DAPI) $[55,56]$ was used to directly introduce ions and the accompanying ambient air into the mass analyzer from the ambient environment. The pressure rises on sample introduction but falls again to levels suitable for mass analysis when the interface is closed. DAPI has been used widely with miniature mass spectrometers $[57,58]$. Unlike the conventional continuous ion introduction technique, DAPI admits discrete pulses of ion/air mixture to reduce the gas load on the pumps. In each sampling period, the DAPI is opened for 10-20 ms under the control of a pulse valve. During this period, ions are pulsed into the vacuum system for subsequent analysis. After the DAPI is closed, the neutral gas is pumped away so that the trapped ions can undergo mass analysis.

\section{Experimental}

All the model standard compounds, 1,2,3,5-tetramethylbenzene, pentamethylbenzene, hexamethylbenzene, fluoranthene, (a)

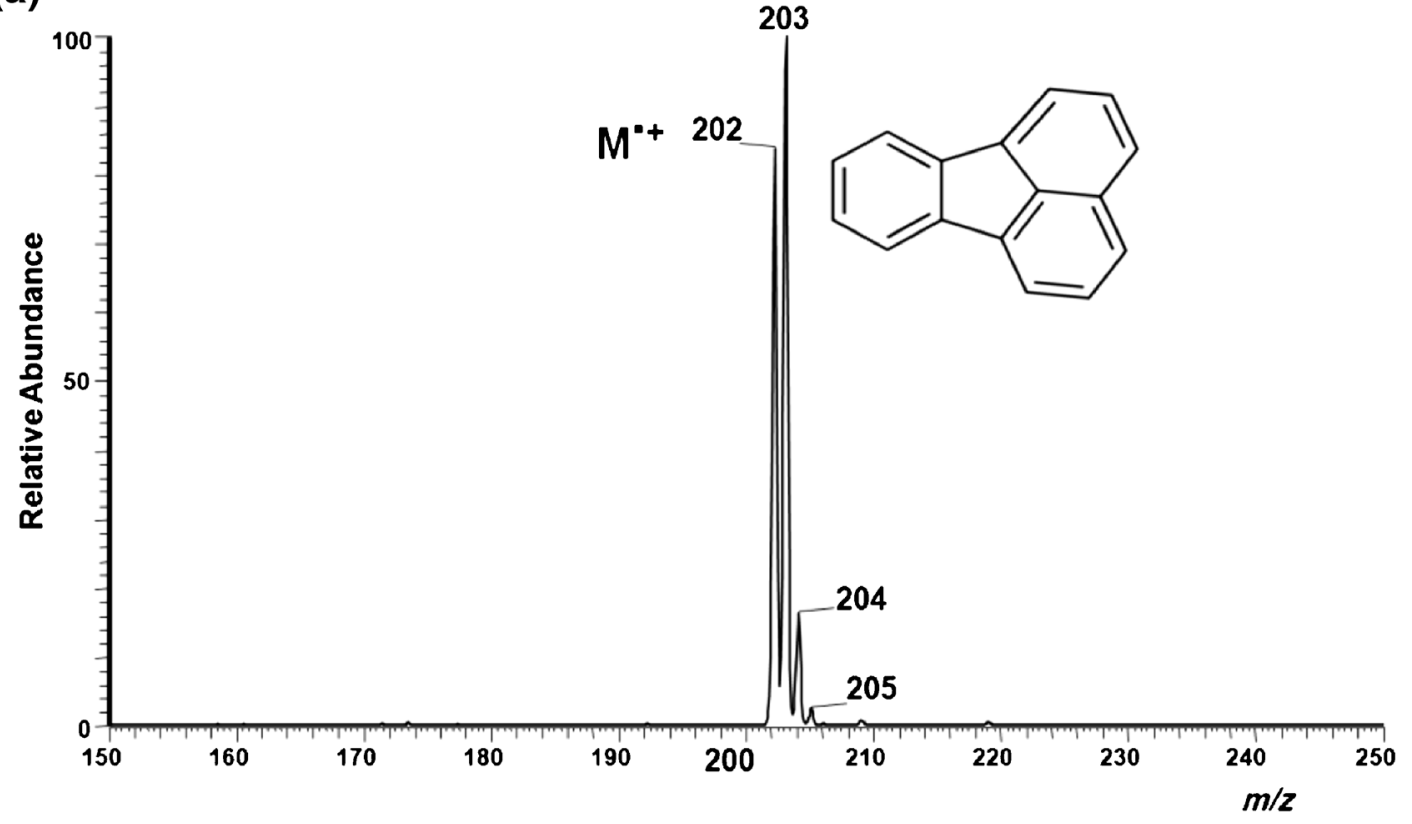

(b)

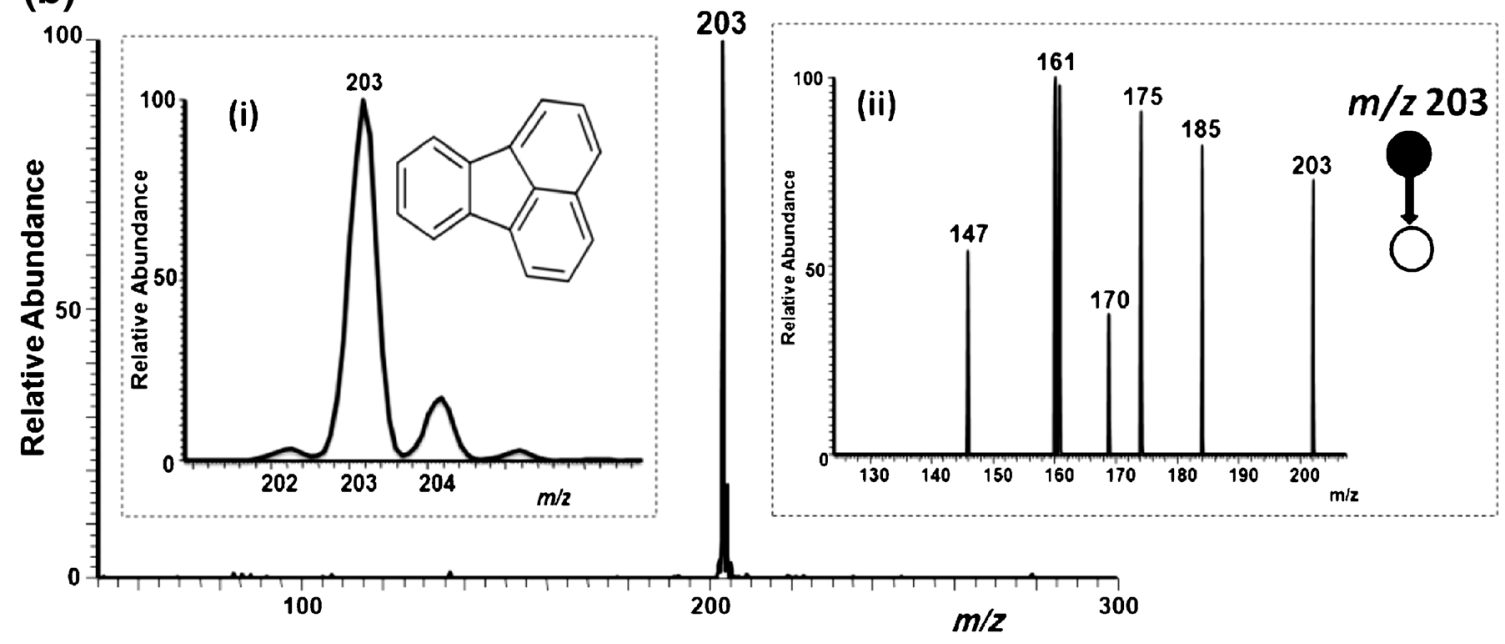

Figure 2. Typical positive ion mode DAPCI mass spectra obtained using a bench-top ion trap instrument. Three $\mathrm{ng}^{\mu} \mathrm{L}^{-1}$ of the analyte(s) in methanol solution was spotted onto the surface and ionized in the open environment by application of an electric potential; (a) protonated fluoranthene $[\mathrm{M}+\mathrm{H}]^{+}(\mathrm{m} / \mathrm{z} 203)$, molecular radical cations at $\mathrm{m} / \mathrm{z} 202$ at $3.5 \mathrm{~L} / \mathrm{min}$ carrier gas flow rate; (b) only protonated molecular species $[\mathrm{M}+\mathrm{H}]^{+}$of fluoranthene $[\mathrm{M}+\mathrm{H}]^{+}(\mathrm{m} / \mathrm{z} 203)$ at $1 \mathrm{~L} / \mathrm{min}$ carrier gas flow rate was observed. Insert (i) shows the isotopic distribution of the analyte ion and insert (ii) shows MS/MS CID data for the selected ions again using 3 ng $\mu L^{-1}$ of analyte in methanol solution 
anthracene, benzo $[k]$ fluoranthene, dibenz $[a, h]$ anthracene, acenaphthene, indeno[1,2,3-c,d]pyrene, 9-ethylfluorene, and 1-benzyl-3-methyl-naphthalene, were purchased from SigmaAldrich (St. Louis, MO, USA) and used directly without further purification. SAFETY NOTE: Most of these compounds are known carcinogens. HPLC grade solvent (methanol) was purchased from Mallinckrodt Baker Inc. (Phillipsburg, NJ, USA). Solutions were made up in methanol to the target concentration using stepwise dilution. In all experiments, sample preparation step was reduced to dilution of the model compounds in methanol solvent only.

In these experiments, a commercial bench-top linear ion trap mass spectrometer (Thermo LTQ, San Jose, CA, USA) was used for the initial experiments. The instrument was set to record mass spectra in the automatic gain control mode for a maximum ion trap injection time of $100 \mathrm{~ms}$; three microscans were combined per spectrum as shown in Supplementary Figure S1 (Supporting Information). MS/MS for the structural elucidation was performed on the isolated molecular ions of interest using collision-induced dissociation (CID) to confirm the presence and identity of the analyte(s) [48]. These experiments were performed using an isolation window of 1.5 Thomson (Th. mass/charge units) and normalized collision energy of $25 \%-40 \%$ (manufacturer's unit). Mass and collisional energy calibration were carried out following the manufacturer's instructions. (a)

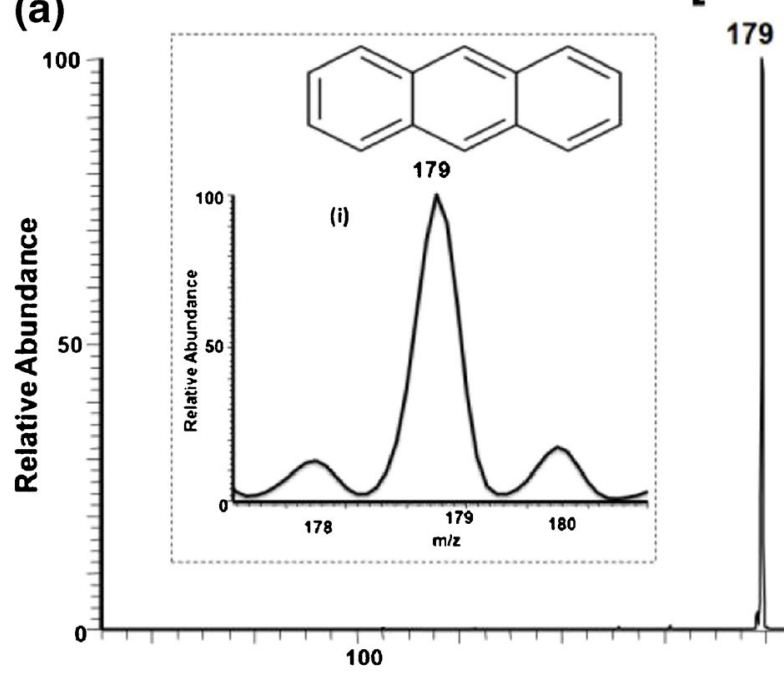

\section{$[\mathrm{M}+\mathrm{H}]^{+}$}

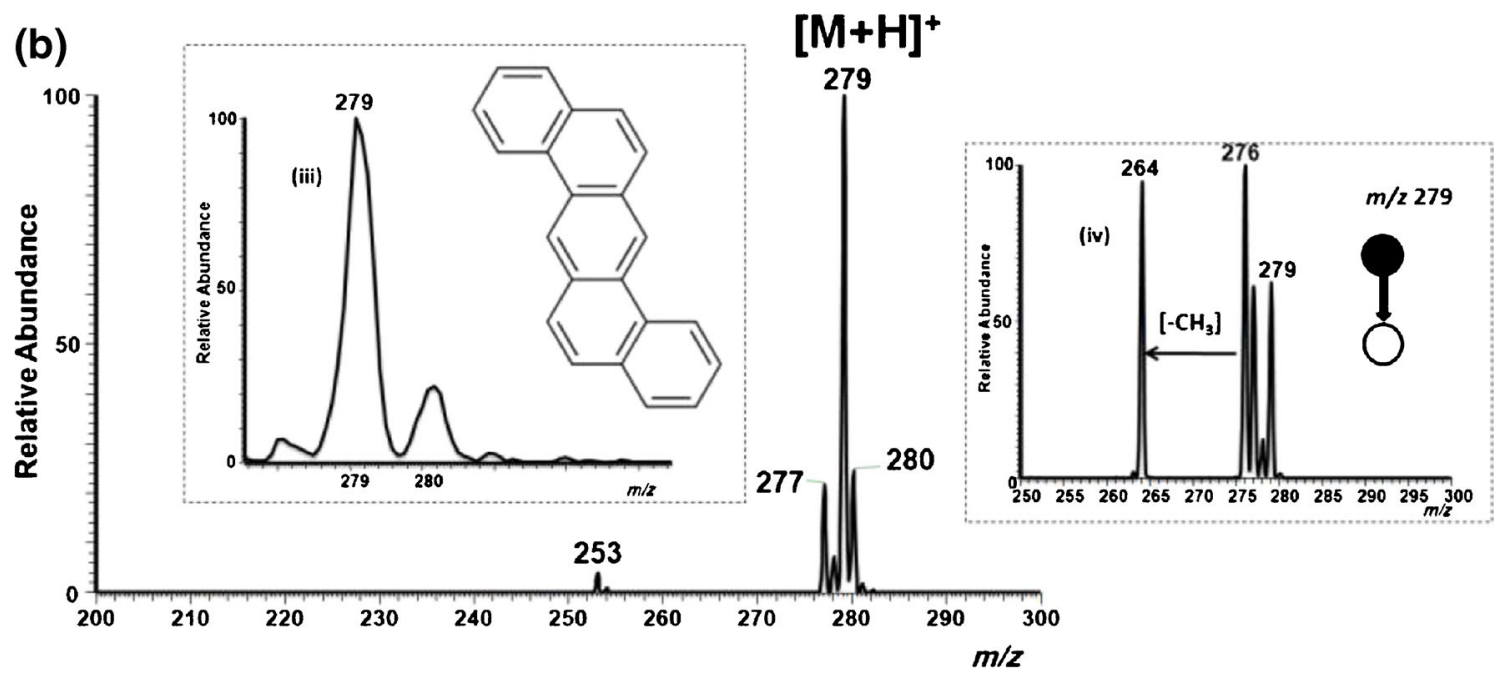

Figure 3. Typical positive ion mode DAPCI mass spectra obtained using a bench-top ion trap instrument. Three ng $\mu \mathrm{L}^{-1}$ of the analyte(s) in methanol solution was spotted onto the surface and ionized in the open environment by application of an electric potential; (a) protonated anthracene $[\mathrm{M}+\mathrm{H}]^{+}\left(\mathrm{m} / \mathrm{z}\right.$ 179); (b) protonated dibenz $[a, h]$ anthracene $[\mathrm{M}+\mathrm{H}]^{+}(\mathrm{m} / z$ 279). Inserts (i) and (iii) show the isotopic distribution of the analyte ion and insert (ii) and (iv) show MS/MS CID data for the selected ions using 3 ng $\mu L^{-1}$ of each analyte in methanol solution for anthracene and dibenz $[a, h]$ anthracene, respectively 
In-situ Analysis Using a Portable Mass

\section{Spectrometer}

The DAPCI ion source was held $2.5 \mathrm{~mm}$ away from the inlet of the Mini 10 mass spectrometer, as shown in Figure 1, to achieve rapid direct analysis of untreated samples under ambient conditions. Results from the in situ analysis experiment were compared with those from a commercial bench-top instrument operating in a typical lab setting.

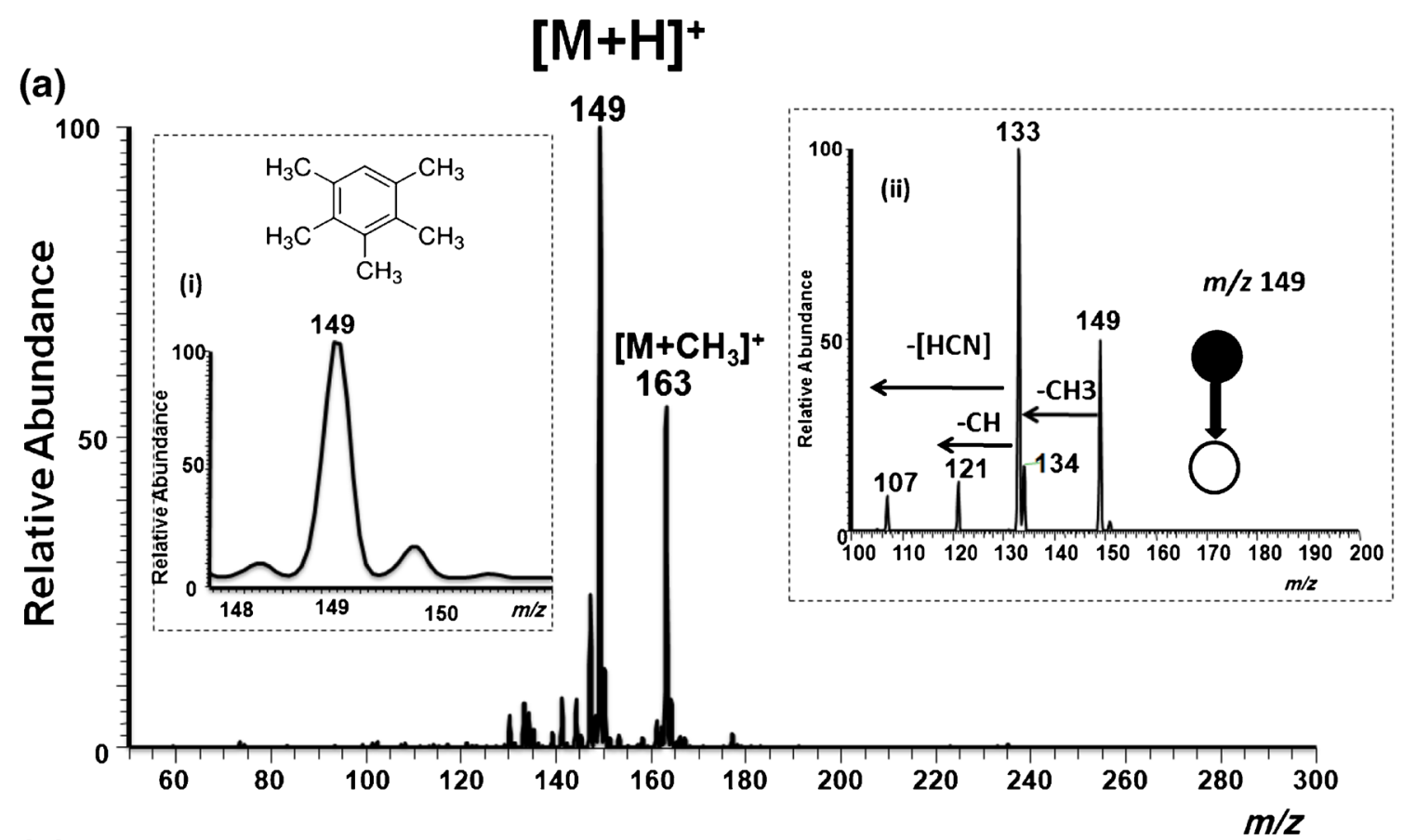

(b)

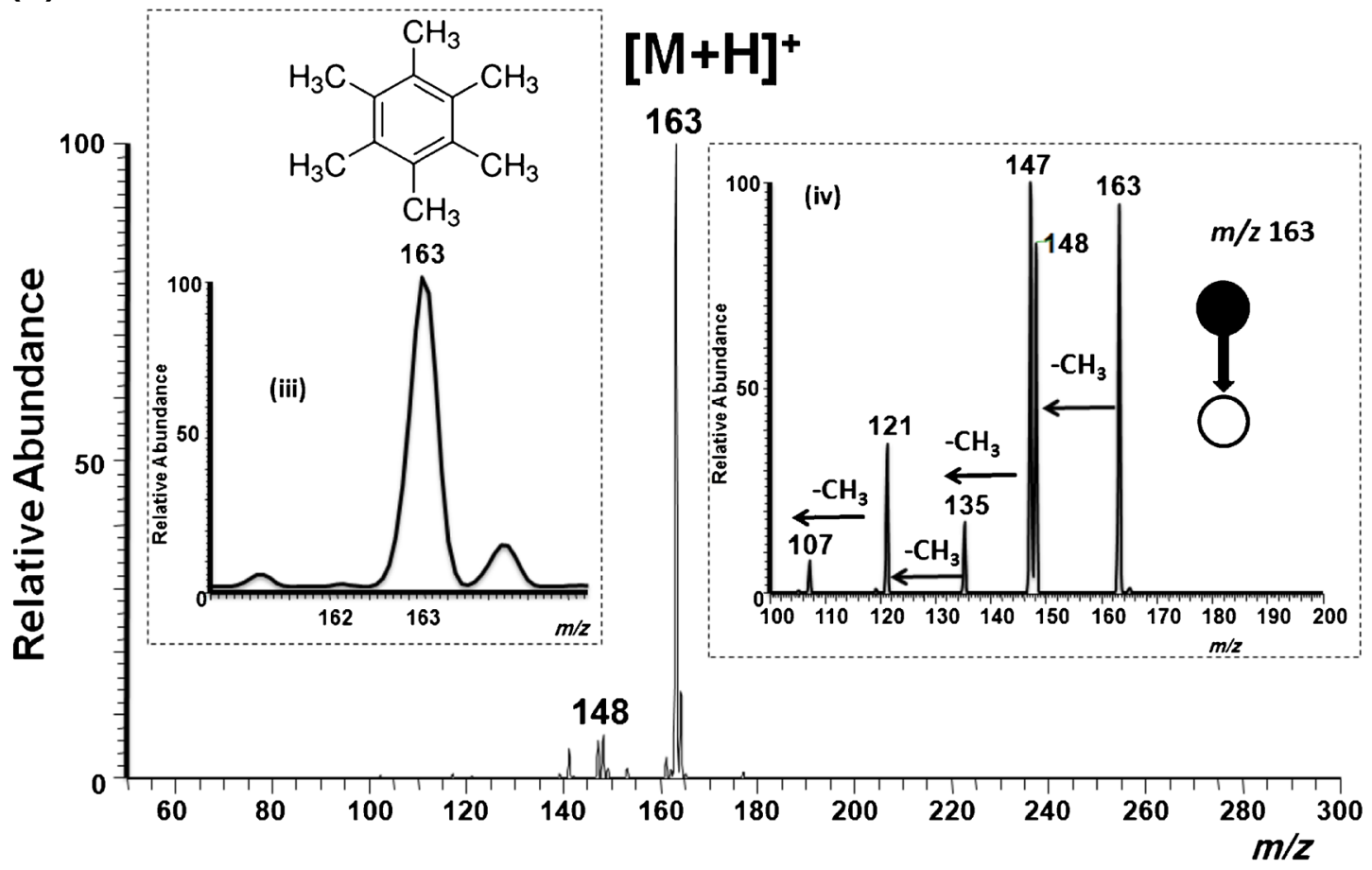

Figure 4. Typical positive ion mode DAPCI mass spectra obtained using a bench-top ion trap instrument. Three ng $\mu \mathrm{L}^{-1}$ of the analyte(s) in methanol solution was spotted onto the surface and ionized in the open environment by application of an electric potential; (a) protonated pentamethylbenzene $[\mathrm{M}+\mathrm{H}]^{+}\left(\mathrm{m} / \mathrm{z}\right.$ 149); (b) protonated hexamethylbenzene $[\mathrm{M}+\mathrm{H}]^{+}(\mathrm{m} / \mathrm{z} 163)$. Inserts (i and iii) show the isotopic distribution of the analyte ion, and inserts (ii) and (iv) show MS/MS CID data for the selected ions again using

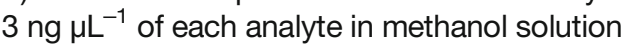




\section{Results and Discussion}

\section{Analysis of Alkylated Benzenes and PAHs Using a Commercial Bench-Top Mass Spectrometer}

Analysis of the plasma generated from the DAPCI probe operated in ambient air, under the open laboratory environment, showed the presence of water cluster ions. In other words, the primary probing ions from a DAPCI source are protonated water clusters, which are able to facilitate analyte(s) ionization via proton transfer [59]. However, the DAPCI parameters, which include carrier flow rate, applied electric potential, and distance from the DAPCI tip to the MS inlet, all influence the type of ions that are observed in DAPCI MS [38,
42]. For this reason, DAPCI ionization was first optimized to only ionize the PAHs via proton transfer reaction; we used an optimized flow rate of $1 \mathrm{~L} / \mathrm{min}$, and a DAPCI potential of $+3 \mathrm{kV}$. For instance, at a high carrier gas flow rate $(>3 \mathrm{~L} /$ $\mathrm{min})$, both molecular radical cations $\left(\mathrm{M}^{+\cdot}\right)$ and protonated molecular species $\left([\mathrm{M}+\mathrm{H}]^{+}\right)$were observed in our experiment (Figure 2). For example, when $3 \mathrm{ng} / \mu \mathrm{L}$ of fluoranthene (MW 202) was applied on the paper surface and analyzed using DAPCI-MS, two intense peaks at $\mathrm{m} / \mathrm{z} 202$ and 203 (molecular radical cations $\mathrm{M}^{+\cdot}$ and protonated molecules $[\mathrm{M}+\mathrm{H}]^{+}$) were observed. At $1 \mathrm{~L} /$ min flow rate, however, only the protonated molecular species $[\mathrm{M}+\mathrm{H}]^{+}$of fluoranthene (MW 202) at $\mathrm{m} / \mathrm{z}$ 203 was observed (Figure $2 b$ ). The identity of the protonated

Table 1. Summary of Alkylated Benzenes and Polycyclic Aromatic Hydrocarbons (PAHs)

\begin{tabular}{|c|c|c|c|}
\hline Compound name & Chemical structure & $\begin{array}{c}\text { Molecular } \\
\text { weight }\end{array}$ & $\begin{array}{c}\text { Ion species } \\
\text { detected }\end{array}$ \\
\hline Anthracene & & 178 & {$[\mathrm{M}+\mathrm{H}]^{+}$} \\
\hline Dibenz $[a, h]$ Anthracene & & 278 & {$[\mathrm{M}+\mathrm{H}]^{+}$} \\
\hline Fluoranthene & & 203 & {$[\mathrm{M}+\mathrm{H}]^{+}$} \\
\hline Benzo[ $k]$ fluoranthene & & 253 & {$[\mathrm{M}+\mathrm{H}]^{+}$} \\
\hline Acenaphthene & & 155 & {$[\mathrm{M}+\mathrm{H}]^{+}$} \\
\hline Indeno[1,2,3-c,d]pyrene & & 276 & {$[\mathrm{M}+\mathrm{H}]^{+}$} \\
\hline $\begin{array}{l}\text { 1-Benzyl-3-methyl- } \\
\text { naphthalene }\end{array}$ & & 232 & $\begin{array}{c}{[\mathrm{M}+\mathrm{H}]^{+}} \\
\mathrm{M}^{+\cdot}\end{array}$ \\
\hline 9- Ethylfluorene & $\mathrm{CH}_{3}$ & 194 & $\begin{array}{l}{[\mathrm{M}+\mathrm{H}]^{+}} \\
{[\mathrm{M}-\mathrm{H}]^{+}}\end{array}$ \\
\hline Pentamethylbenzene & $\mathrm{H}_{3} \mathrm{C}^{-}$ & 148 & $\begin{array}{c}{[\mathrm{M}+\mathrm{H}]^{+}} \\
{[\mathrm{M}-\mathrm{H}]^{+}} \\
{\left[\mathrm{M}-\mathrm{CH}_{3}\right]^{+}}\end{array}$ \\
\hline Hexamethylbenzene & & 162 & {$[\mathrm{M}+\mathrm{H}]^{+}$} \\
\hline $\begin{array}{l}\text { 1,2,3,5-Tetramethyl } \\
\text { benzene }\end{array}$ & & 134 & {$[\mathrm{M}+\mathrm{H}]^{+}$} \\
\hline
\end{tabular}


molecule was confirmed using tandem mass spectrometry as shown in insert (ii) of Figure 2. In subsequent experiments, we analyzed other PAHs under ionization conditions that predominantly favored proton transfer reactions as the ionization mechanism of DAPCI - we used a carrier gas flow rate of $1 \mathrm{~L} / \mathrm{min}$ while also maintaining other parameters such DAPCI potential at $+3 \mathrm{kV}$, and distance between DAPCI and mass spectrometer inlet at $2.5 \mathrm{~mm}$.

For the analysis of other PAHs, we applied $\sim 3 \mathrm{ng} \mu \mathrm{L}^{-1}(1 \mu \mathrm{L}$ of $100 \mathrm{ppm}$ solution) of each sample solution prepared in methanol to a cellulose chromatography paper surface (Whatman Grade 1; Maidstone, UK) and recorded the data using a commercial instrument (see Supplementary Figure S1, Supporting Information for details). The resulting mass spectra showed intact protonated molecules $[\mathrm{M}+\mathrm{H}]^{+}$with little or no fragmentation, and no interfering radical cations. The absence of signal due to background ions from the DAPCI source is consistent with the high ionization efficiency of most PAHs, and reflects their relatively high proton affinities (PA, a well-known feature of many PAHs analyzed using chemical ionization [42]. For instance, the mass spectra recorded for dibenz $[a, h]$ anthracene (MW 278), anthracene (MW 178) showed mainly the protonated molecule $[\mathrm{M}+\mathrm{H}]^{+}$(Figure $3 \mathrm{a}, \mathrm{b}$ ).

Identification of each individual intact protonated molecule was achieved using MS/MS through CID experiments. For instance, the dissociation of dibenz $[a, h]$ anthracene molecular ion of $\mathrm{m} / \mathrm{z} 279$ provided a fragment ion at $\mathrm{m} / \mathrm{z} 264$ via the loss of methyl radical (-15 Da, $\mathrm{CH}_{3}$ ), Figure 3 insert (iv). Although this fragmentation pathway is not common for many protonated organic compounds, the CID fragmentation pattern of dibenz $[a, h]$ anthracene $m / z 279$ and anthracene (MW 178) ions observed in this experiment resembles the common fragmentation mechanisms seen for most ionic PAHs [60]: (1) formation of $\left[\mathrm{M}-\mathrm{H}_{\mathrm{n}}\right]^{+}$fragment ions, and (2) ring opening and extensive isomerization leading to $\mathrm{CH}_{3}$ and $\left(\mathrm{CH}_{2}\right)_{\mathrm{n}}(\mathrm{n}>1)$ losses [60]. Interestingly, unlike high energy collision processes, the low mass fragment ionic series $\left[\mathrm{C}_{\mathrm{n}} \mathrm{H}_{2}\right]^{+}$and $\left[\mathrm{C}_{\mathrm{n}} \mathrm{H}_{3}\right]^{+}$are not observed in our CID experiments.

Similarly, other alkylated benzenes and PAHs including 1,2,3,5-tetramethylbenzene, pentamethylbenzene, hexamethylbenzene, benzo[ $k]$ fluoranthene, acenaphthene, indeno(1,2,3-c,d)pyrene, and 9-ethylfluorene were analyzed using DAPCI-MS from the paper surface using the Thermo LTQ bench-top commercial instrument (see Supplementary Figure S2.1 and S2.2, Supporting Information, for the mass spectra and CID data). For example, Figure 4 shows positive ion mode DAPCI mass spectrum obtained for the protonated molecule of alkyl substituted benzenes; Figure 4a: pentamethyl benzene (MW 148), and Figure 4b: hexamethyl benzene (MW 162). Again, characterization of each individual intact protonated molecule was achieved using MS/MS CID. For instance, inserts (iii) and (iv) Figure 4 show that CID of the intact protonated $[\mathrm{M}+\mathrm{H}]^{+}$of pentamethyl benzene at $m / z \quad 149$ yields a single fragment ion of tetramethyl benzene molecule, which is deprotonated at $\mathrm{m} / z 133 \mathrm{via}$ a loss of methyl radical (insert (iii), Figure 4). Also the protonated hexamethyl benzene molecule $[\mathrm{M}+\mathrm{H}]^{+}$at $\mathrm{m} / \mathrm{z} 163$ followed the same CID dissociation fragmentation pattern with the loss of a methyl radical to give a

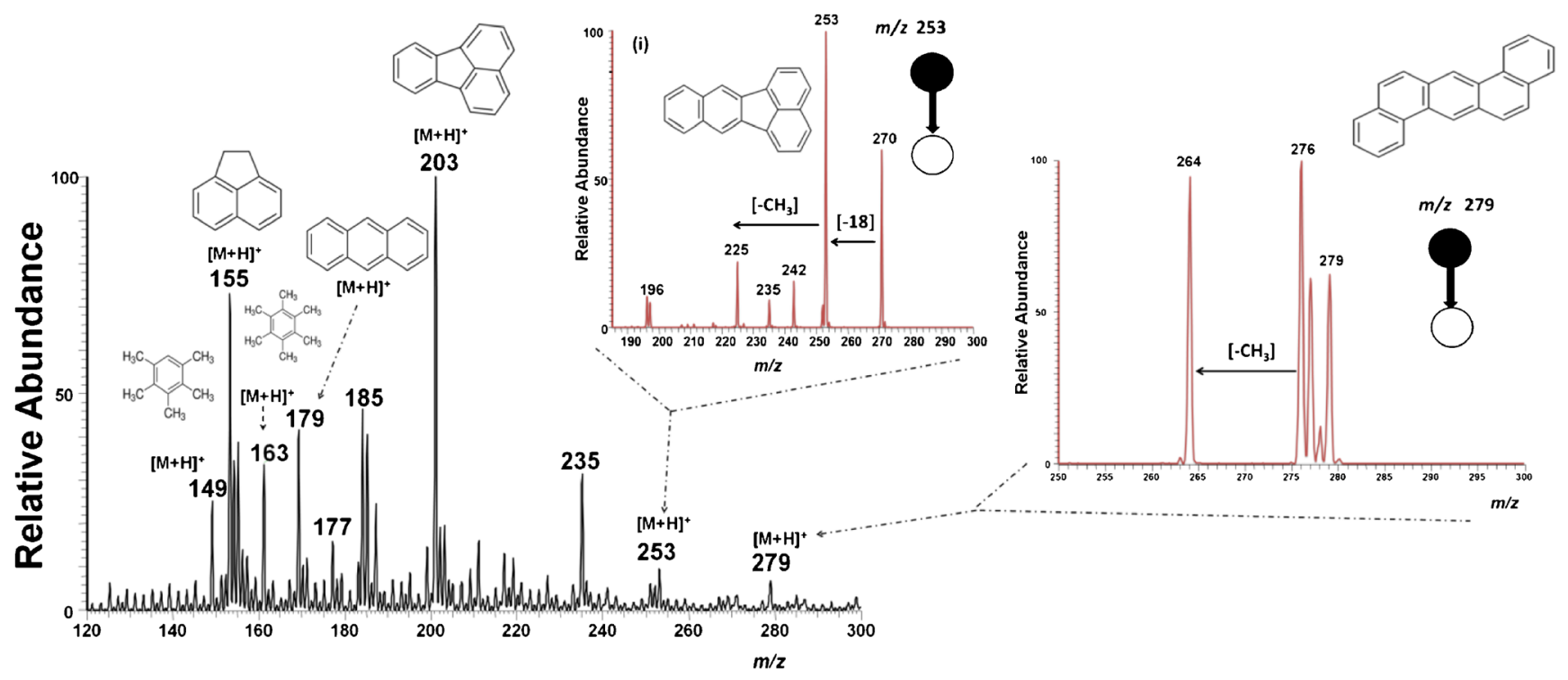

Figure 5. Positive ion mode DAPCI mass spectrum for a mixture of several of the model compounds analyzed using a bench-top instrument. All the compounds in the mixture gave intact protonated molecular species $[\mathrm{M}+\mathrm{H}]^{+}$of pentamethylbenzene $(\mathrm{m} / z 149)$, acenaphthene ( $\mathrm{m} / \mathrm{z}$ 155), pentamenthylbenzene $(\mathrm{m} / \mathrm{z} 163)$, anthracene $(\mathrm{m} / \mathrm{z} 179)$, fluoranthene $(\mathrm{m} / z$ 203), benzo[ $\mathrm{k}] \mathrm{fluoranthene}(\mathrm{m} / \mathrm{z}$ 253), and dibenz $[a, h]$ anthracene $(\mathrm{m} / z$ 279). Absolute amounts of analyte(s) spotted onto the surface and ionized in open environment by application of an electric potential were $5 \mathrm{ng} \mathrm{\mu L}^{-1}$ in methanol solution; inserts (i) and (ii) show MS/MS CID data for benzo[ $k$ fluoranthene $(\mathrm{m} / \mathrm{z} 253)$, and for dibenz[a,h]anthracene $(\mathrm{m} / \mathrm{z} 279)$ protonated molecules using $3 \mathrm{ng} \mu \mathrm{L}^{-1}$ of each analyte in methanol solution 
deprotonated pentamethyl benzene fragment ion at $\mathrm{m} / \mathrm{z}$ 147. Such fragmentation patterns from the multi-stage tandem mass spectrometry experiment allow definitive confirmation of the identity of the analyte [46, 47]. Table 1 provides a summary of data for all the model compounds studied, including their structures and CID fragmentation pattern.

\section{Analysis of PAHs in a Mixture Using DAPCI MS}

DAPCI MS was also applied to the analysis of alkylated benzenes and PAHs in a mixture. For these experiments, an artificial mixture was prepared by mixing equal volumes of the model compounds: pentamethylbenzene, hexamethylbenzene, anthracene, dibenz $[a, h]$ anthracene, fluoranthene, and benzo[k]fluoranthene $(1: 1, \mathrm{v} / \mathrm{v})$. The mixture was then analyzed using the optimal DAPCI ionization conditions that favor protonation under ambient conditions while restricting sample preparation to just dissolving the model compounds in methanol solvent. Approximately $3 \mathrm{ng} \mu \mathrm{L}^{-1}$ of each compound (mixed in methanol solution) was spotted onto the paper substrate and analyzed using the commercial ion trap bench-top mass spectrometer. Figure 5a shows the mass spectra obtained from the analysis of the PAH mixture using DAPCI MS. Again, as observed for the individual PAH analysis, intact protonated molecules were observed $[\mathrm{M}+\mathrm{H}]^{+}$, and each individual molecule was characterized using MS/MS CID dissociation to identify each component in the mixture. The ability to restrict ion formation by proton transfer processes simplifies the resulting mass spectra in the case of mixture analysis without prior separation. The inserts (i) and (ii) in Figure 5 show the CID data for the protonated benzo[ $k]$ fluoranthene and dibenz $[a, h]$ anthracene ions, respectively. The PAHs mixture gave excellent stable DAPCI mass spectra and produced no observable ion fragmentations in the full scan mass spectrum mode.

\section{Direct Analysis of Alkylated Benzenes and PAHs Using a Portable Mass Spectrometer (Mini 10) with DAPCI}

The successful analysis of alkylated benzenes and PAHs using a commercial bench-top mass spectrometer with DAPCI encouraged us to transfer this experiment to a miniature ion trap mass

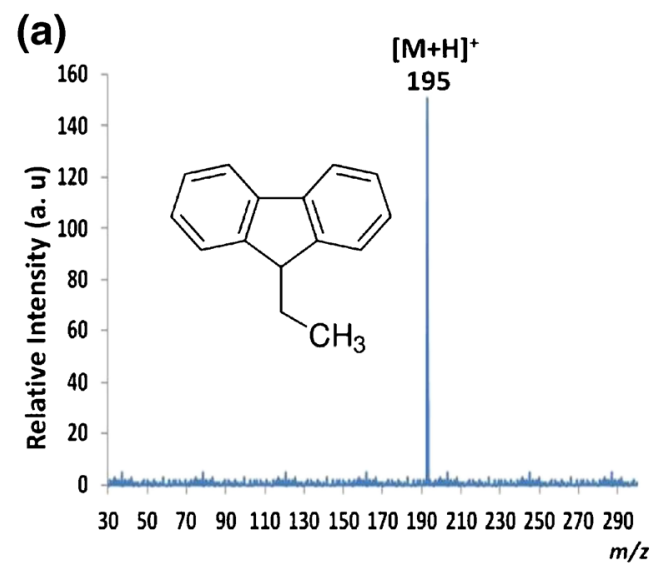

(c)

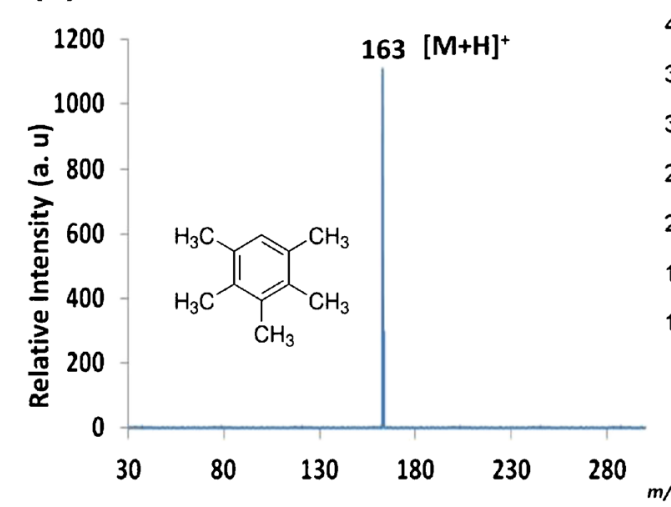

(b)

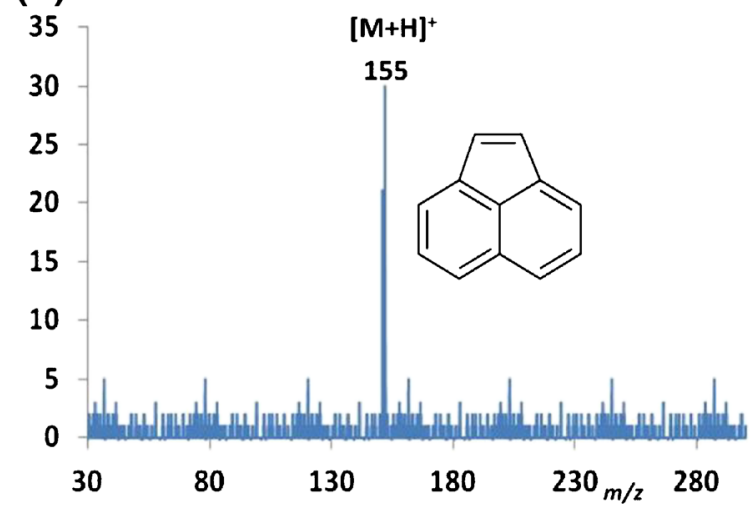

(d)

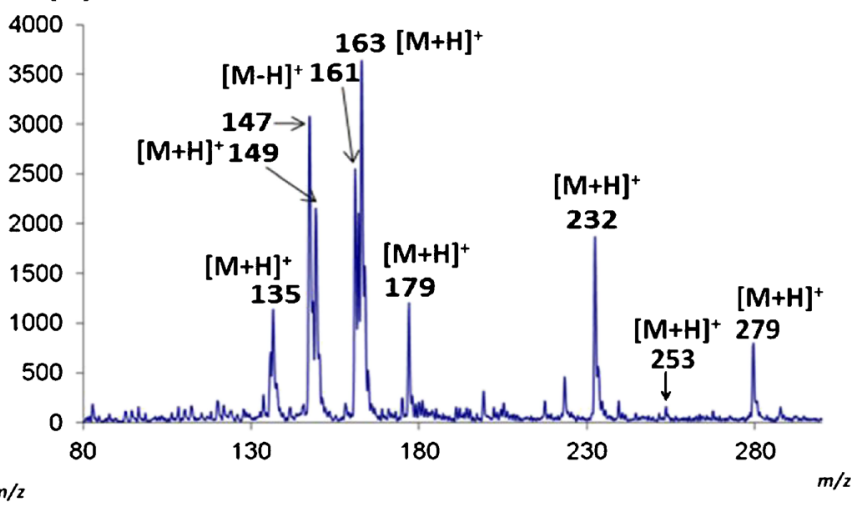

Figure 6. Positive ion mode DAPCI mass spectra using a portable instrument. Three $\mathrm{ng} \mathrm{L}^{-1}$ of the analyte(s) in methanol solution was spotted onto the surface and ionized in the open environment by application of an electric potential; (a) protonated 9ethylfluorene $[\mathrm{M}+\mathrm{H}]^{+}\left(\mathrm{m} / \mathrm{z}\right.$ 195), (b) protonated acenaphthene $[\mathrm{M}+\mathrm{H}]^{+} \mathrm{m} / \mathrm{z} 155$, (c) protonated hexamethylbenzene $[\mathrm{M}+\mathrm{H}]^{+}(\mathrm{m} / z$ 163), and (d) seven PAHs model compounds in a mixture examined on a surface (paper substrate) analyzed using a potable mass spectrometer. All the compounds in the mixture gave intact protonated molecular species $[\mathrm{M}+\mathrm{H}]^{+}$; pentamethylbenzene $(\mathrm{m} / z \mathrm{z}$ 149), hexamenthylbenzene $(\mathrm{m} / \mathrm{z} 163)$, anthracene $(\mathrm{m} / \mathrm{z} 179)$, benyl-3-methylnapthalene $(\mathrm{m} / \mathrm{z} 232)$, benzo[ $\mathrm{k}] \mathrm{fluoranthene}(\mathrm{m} / \mathrm{z} 253)$, and dibenz $[a, h]$ anthracene $(m / z 279)$ 
spectrometer (Mini 10). Mixtures as well as individual PAHs were analyzed in the same manner (as above) using the Mini 10 coupled with a DAPCI ion source. For example, Figure $6 \mathrm{a}-\mathrm{c}$ show mass spectra for $3 \mathrm{ng} \mu \mathrm{L}^{-1}$ 9-ethylflourene $[\mathrm{M}+\mathrm{H}]^{+}$, at $m / z 195$, acenaphthene $[\mathrm{M}+\mathrm{H}]^{+}$, at $m / z 155$, and hexamethylbenzene $[\mathrm{M}+\mathrm{H}]^{+}$, at $m / z 163$, respectively. Other model PAHs analyzed using DAPCI with a portable mass spectrometer included 1,2,3,5-tetramethylbenzene, pentamethylbenzene, and benzyl-3-methylnapthalene (see Supplementary Figure 3, Supporting Information for more detail). As can be observed, coupling the DAPCI ion source to a portable mass spectrometer (Mini 10) gives a high signal-to-noise ratio even at this low level of analyte $3 \mathrm{ng} \mu \mathrm{L}^{-1}$ (Figure 6d).

Both the commercial and the home built Mini 10 mass spectrometers give high ion signal-to-noise ratios that allow the identity of alkylated benzenes and PAHs to be readily confirmed by MS/MS. Even though the Mini 10 operates at a relatively higher pressure compared with the commercial instrument used, little fragmentation was observed in the full scan mass spectra as shown in Figure 6a-c.

The combination of the DAPCI and Mini 10 was also used for PAH mixture analysis. A standard mixture $(1: 1 \mathrm{v} / \mathrm{v})$ of pentamethylbenzene (MW 149), acenaphthalene (MW 154), hexamenthylbenzene (MW 163), anthracene (MW 179), fluoranthene (MW 203), benzo[k]fluoranthene (MW 252), dibenz $[a, h]$ anthracene (MW 278), and benyl-3methylnapthalene were dissolved in methanol solution. Figure $6 \mathrm{~d}$ shows all the components ( $3 \mathrm{ng} \mu \mathrm{L}^{-1}$ each) in the mixture were observed in the full scan mode with a portable mass spectrometer at expected $\mathrm{m} / \mathrm{z}$ of $[\mathrm{M}+\mathrm{H}]^{+}$: pentamethylbenzene at $\mathrm{m} / \mathrm{z} 149$, acenaphthalene at $\mathrm{m} / \mathrm{z} 155$, pentamenthylbenzene at $\mathrm{m} / \mathrm{z} 163$, anthracene at $\mathrm{m} / \mathrm{z} 179$, fluoranthene at $\mathrm{m} / \mathrm{z} 203$, benzo[ $k]$ fluoranthene at $\mathrm{m} / z$ 253, and dibenz $[a, h]$ anthracene at $m / z$ 279. Here too, the alkylated benzenes and PAHs in the mixture were analyzed from a paper surface.

\section{Conclusion}

The application of DAPCI ambient ionization technique for the direct analysis of condensed phase alkylated benzenes and PAHs using a portable mass spectrometer has been studied. Analysis of different species was achieved through proton transfer reactions and was applied for selective ionization of polar and nonpolar hydrocarbons, individually and in a mixture under open laboratory environment. Fundamental aspects of the ionization process were investigated in terms of ionization mechanism and fragmentation patterns for different PAHs and alkylated benzenes. From the results shown, it is evident that different PAHs and alkylated benzenes can easily be ionized and detected with a DAPCI source coupled with a miniaturized portable mass spectrometer. The combination of DAPCI with a portable mass spectrometer has the potential to be an important analytical tool for in situ analysis of alkylated benzenes and PAHs on surfaces. Future work will involve on-site analysis and quantification of these compounds in real environmental samples. The capabilities of this analytical protocol will be extended to other environmental contaminants (e.g., crude oil) that are also of significant importance. The results shown are of interest beyond the alkylated benzenes and PAHs studied here as they demonstrate the feasibility of in situ analysis using a portable miniaturized mass spectrometer for nonpolar, condensed phase organic chemicals. This method could also be applied to other monitoring applications such as environmental hygiene and accelerant analysis in forensics.

\section{Acknowledgments}

Funding for this research was provided by the National Science foundation (grant numbers NNX12AB16G and CHE0848650). F.P.M.J. acknowledges a research grant from the Department of Electrical Engineering and Electronics, University of Liverpool, UK. A.K.B.-T. acknowledges funding from The Ohio State University start-up funds. A. L. acknowledges funding from NASA-PIDDP (grant number NNX12AB16G).

\section{References}

1. Chaudhary, P., Sharma, R., Singh, S.B., Nain, L.: Bioremediation of PAH by Streptomyces sp. Bull. Environ. Contam. Toxicol. 86, 268-271 (2011)

2. Chen, J.-C., Schwartz, J.: Neurobehavioral effects of ambient air pollution on cognitive performance in US adults. Neurotoxicology. 30, 231-239 (2009)

3. Yang, X., Li, J., Wen, T., Ren, X., Huang, Y., Wang, X.: Adsorption of naphthalene and its derivatives on magnetic graphene composites and the mechanism investigation. Colloids Surf A Physicochem. Eng. Asp. 422, $118-125$ (2013)

4. Hayes, R.B., Dosemeci, M., Wacholder, S., Travis, L.B., Rothman, N., Hoover, R.N., Linet, M.S., Yin, S.-N., Li, G.-L., Li, C.-Y.: Benzene and the dose-related incidence of hematologic neoplasms in China. J. Natl. Cancer. Inst. 89, 1065-1071 (1997)

5. Perera, F.P., Li, Z., Whyatt, R., Hoepner, L., Wang, S., Camann, D., Rauh, V.: Prenatal airborne polycyclic aromatic hydrocarbon exposure and child IQ at age 5 years. Pediatrics. 124, e195-e202 (2009)

6. Seto, Y., Kanamori-Kataoka, M., Tsuge, K., Ohsawa, I., Maruko, H., Sekiguchi, H., Sano, Y., Yamashiro, S., Matsushita, K., Sekiguchi, H.: Development of an on-site detection method for chemical and biological warfare agents. Toxin. Rev. 26, 299-312 (2007)

7. Seto, Y., Kanamori-Kataoka, M., Tsuge, K., Ohsawa, I., Matsushita, K., Sekiguchi, H., Itoi, T., Iura, K., Sano, Y., Yamashiro, S.: Sensing technology for chemical-warfare agents and its evaluation using authentic agents. Sensors Actuators B. Chem. 108, 193-197 (2005)

8. Zhang, R., Yu, X., Yin, Y., Ye, Z., Wang, G., Yuan, J.: Development of a heterobimetallic $\mathrm{Ru}$ (II)-Cu (II) complex for highly selective and sensitive luminescence sensing of sulfide anions. Anal. Chim. Acta. 691, 83-88 (2011)

9. Arthur, C.L., Killam, L.M., Buchholz, K.D., Pawliszyn, J., Berg, J.R.: Automation and optimization of solid-phase microextraction. Anal. Chem. 64, 1960-1966 (1992)

10. Maurer, H.H.: Current role of liquid chromatography-mass spectrometry in clinical and forensic toxicology. Anal. Bioanal. Chem. 388, 1315-1325 (2007)

11. Boyaci, E., Pawliszyn, J.: Micelle assisted thin-film solid phase microextraction: a new approach for determination of quaternary ammonium compounds in environmental samples. Anal. Chem. (2014)

12. Maurer, H.H.: Perspectives of liquid chromatography coupled to low-and high-resolution mass spectrometry for screening, identification, and quantification of drugs in clinical and forensic toxicology. Ther. Drug Monit. 32, 324-327 (2010)

13. Richardson, S.D.: Environmental mass spectrometry: emerging contaminants and current issues. Anal. Chem. 84, 747-778 (2011)

14. Lebedev, A.T.: Environmental mass spectrometry. Ann. Rev. Anal. Chem. 6, 163-189 (2013)

15. Poster, D.L., Schantz, M.M., Sander, L.C., Wise, S.A.: Analysis of polycyclic aromatic hydrocarbons (PAHs) in environmental samples: a critical 
review of gas chromatographic (GC) methods. Anal. Bioanal. Chem. 386, 859-881 (2006)

16. Fetzer, J.C.: The chemistry and analysis of large PAHs. Polycycl. Aromat. Compd. 27, 143-162 (2007)

17. Baumard, P., Budzinski, H., Garrigues, P.: Analytical procedure for the analysis of PAHs in biological tissues by gas chromatography coupled to mass spectrometry: application to mussels. Fresenius J. Anal. Chem. 359, 502-509 (1997)

18. Li, A., Jjunju, F.P., Cooks, R.G.: Nucleophilic addition of nitrogen to aryl cations: Mimicking titan chemistry. J. Am. Soc. Mass. Spectrom. 24, 17451754 (2013)

19. Monge, M.E., Harris, G.A., Dwivedi, P., Fernández, F.M.: Mass spectrometry: recent advances in direct open air surface sampling/ionization. Chem. Rev. 113, 2269-2308 (2013)

20. Harris, G.A., Galhena, A.S., Fernandez, F.M.: Ambient sampling/ ionization mass spectrometry: applications and current trends. Anal. Chem. 83(4508-4538) (2011)

21. Harris, G.A., Nyadong, L., Fernandez, F.M.: Recent developments in ambient ionization techniques for analytical mass spectrometry. Analyst. 133(1297-1301) (2008)

22. Culzoni, M.J., Dwivedi, P., Green, M.D., Newton, P.N., Fernandez, F.M.: Ambient mass spectrometry technologies for the detection of falsified drugs. Med. Chem. Commun. 5, 9-19 (2014)

23. Li, L.P., Feng, B.S., Yang, J.W., Chang, C.L., Bai, Y., Liu, H.W.: Applications of ambient mass spectrometry in high-throughput screening. Analyst. 138, 3097-3103 (2013)

24. Maher, S., Syed, S.U., Hughes, D.M., Gibson, J.R., Taylor, S.: Mapping the stability diagram of a quadrupole mass spectrometer with a static transverse magnetic field applied. J. Am. Soc. Mass Spectrom. 24, 1307-1314 (2013)

25. Mulligan, C.C., Talaty, N., Cooks, R.G.: Desorption electrospray ionization with a portable mass spectrometer: in situ analysis of ambient surfaces Chem. Commun. 16, 1709-1711 (2006)

26. Short, R.T., Toler, S.K., Kibelka, G.P.G., Rueda Roa, D.T., Bell, R.J., Byrne, R.H.: Detection and quantification of chemical plumes using a portable underwater membrane introduction mass spectrometer. TrAC Trends. Anal. Chem. 25, 637-646 (2006)

27. Ouyang, Z., Cooks, R.G.: Miniature mass spectrometers. Annu. Rev. Anal. Chem. 2, 187-214 (2009)

28. Cooks, R.G., Ouyang, Z., Takats, Z., Wiseman, J.M.: Ambient mass spectrometry. Science. 311, 1566-1570 (2006)

29. Takats, Z., Wiseman, J.M., Cooks, R.G.: Ambient mass spectrometry using desorption electrospray ionization (DESI): instrumentation, mechanisms and applications in forensics, chemistry, and biology. J. Mass Spectrom. 40, 1261-1275 (2005)

30. Takats, Z., Wiseman, J.M., Gologan, B., Cooks, R.G.: Mass spectrometry sampling under ambient conditions with desorption electrospray ionization. Science. 306, 471-473 (2004)

31. Cody, R.B.: Observation of molecular ions and analysis of nonpolar compounds with the direct analysis in real time ion source. Anal. Chem. 81, 1101-1107 (2009)

32. Cody, R.B., Laramee, J.A., Durst, H.D.: Versatile new ion source for the analysis of materials in open air under ambient conditions. Anal. Chem. 77, 2297-2302 (2005)

33. Zhang, S.-Y., Li, G., Wu, H.-B., Liu, X.-G., Yao, Y.-H., Tao, L., Liu, H.: An integrated recirculating aquaculture system (RAS) for land-based fish farming: the effects on water quality and fish production. Aquacult. Eng. 45, 93-102 (2011)

34. Harper, J.D., Charipar, N.A., Mulligan, C.C., Zhang, X., Cooks, R.G., Ouyang, Z.: Low-temperature plasma probe for ambient desorption ionization. Anal. Chem. 80, 9097-9104 (2008)

35. Wang, H., Liu, J., Cooks, R., Ouyang, Z.: Paper spray for direct analysis of complex mixtures using mass spectrometry. Angew. Chem. 122, 889-892 (2010)

36. Li, A., Wang, H., Ouyang, Z., Cooks, R.G.: Paper spray ionization of polar analytes using non-polar solvents. Chem Commun 47, 2811-2813 (2011)

37. Jjunju, F.P., Li, A., Badu-Tawiah, A., Wei, P., Li, L., Ouyang, Z., Roqan, I.S., Cooks, R.G.: In situ analysis of corrosion inhibitors using a portable mass spectrometer with paper spray ionization. Analyst. 138, 3740-3748 (2013)

38. Cotte-Rodríguez, I., Mulligan, C.C., Cooks, R.G.: Non-proximate detection of small and large molecules by desorption electrospray ionization and desorption atmospheric pressure chemical ionization mass spectrometry: instrumentation and applications in forensics, chemistry, and biology. Anal. Chem. 79, 7069-7077 (2007)
39. Luosujarvi, L., Kanerva, S., Saarela, V., Franssila, S., Kostiainen, R. Kotiaho, T., Kauppila, T.J.: Environmental and food analysis by desorption atmospheric pressure photoionization-mass spectrometry. Rapid. Commun. Mass Spectrom. 24, 1343-1350 (2010)

40. Yang, S., Ding, J., Zheng, J., Hu, B., Li, J., Chen, H., Zhou, Z., Qiao, X: Detection of melamine in milk products by surface desorption atmospheric pressure chemical ionization mass spectrometry. Anal. Chem. 81, 24262436 (2009)

41. Chen, H., Liang, H., Ding, J., Lai, J., Huan, Y., Qiao, X.: Rapid differentiation of tea products by surface desorption atmospheric pressure chemical ionization mass spectrometry. J. Agri. Food Chem. 55, 10093-10100 (2007)

42. Jjunju, F.P., Badu-Tawiah, A.K., Li, A., Soparawalla, S., Roqan, I.S., Cooks, R.G.: Hydrocarbon analysis using desorption atmospheric pressure chemical ionization. Int. J. Mass Spectrom. 345, 80-88 (2013)

43. Mulligan, C.C., MacMillan, D.K., Noll, R.J., Cooks, R.G.: Fast analysis of high-energy compounds and agricultural chemicals in water with desorption electrospray ionization mass spectrometry. Rapid. Commun. Mass Spectrom. 21, 3729-3736 (2007)

44. Fallahtafti, S., Rantanen, T., Brown, R.S., Snieckus, V., Hodson, P.V.: Toxicity of hydroxylated alkyl-phenanthrenes to the early life stages of Japanese medaka (Oryzias latipes). Aquat. Toxicol. 106, 56-64 (2012)

45. Hawthorne, S.B., Miller, D.J., Kreitinger, J.P.: Measurement of total polycyclic aromatic hydrocarbon concentrations in sediments and toxic units used for estimating risk to benthic invertebrates at manufactured gas plant sites. Environ. Toxicol. Chem. 25, 287-296 (2006)

46. Jackson, A.T., R.C.K.J., H.T. Yates, Scrivens, J.H., Jennings, K.R.: Utilizing precursor ion and second-generation product ion scanning techniques in a four-sector mass spectrometer for the analysis of polymer additives. Eur. Mass Spectrom. 3, 113-120 (1997)

47. Jackson, A.T., Williams, J.P., Scrivens, J.H.: Desorption electrospray ionisation mass spectrometry and tandem mass spectrometry of low molecular weight synthetic polymers. Rapid Commun. Mass Spectrom. 20, 2717-2727 (2006)

48. Gao, Y., McLuckey, S.A.: Collision-induced dissociation of oligonucleotide anions fully modified at the 2 '-position of the ribose: 2 '-f/-h and 2'-f/-h/ome mix-mers. J. Mass Spectrom. 47, 364-369 (2012)

49. Hakansson, K., Cooper, H.J., Hudgins, R.R., Nilsson, C.L.: High resolution tandem mass spectrometry for structural biochemistry. Curr. Org. Chem. 7, $1503-1525$ (2003)

50. Sokol, E., Noll, R.J., Cooks, R.G., Beegle, L.W., Kim, H.I., Kanik, I.: Miniature mass spectrometer equipped with electrospray and desorption electrospray ionization for direct analysis of organics from solids and solutions. Int. J. Mass Spectrom. 306, 187-195 (2011)

51. Xu, W., Manicke, N.E., Cooks, G.R., Ouyang, Z.: Miniaturization of mass spectrometry analysis systems. J. Assoc. Lab. Autom. 15, 433-439 (2010)

52. Gao, L., Song, Q., Patterson, G.E., Cooks, R.G., Ouyang, Z.: Handheld rectilinear ion trap mass spectrometer. Anal. Chem. 78, 5994-6002 (2006)

53. Sanders, N.L., Sokol, E., Perry, R.H., Huang, G., Noll, R.J., Duncan, J.S., Cooks, R.G.: Hand-held mass spectrometer for environmentally relevant analytes using a variety of sampling and ionization methods. Eur. J. Mass Spectrom. 16, 11-20 (2009)

54. Gao, L., Sugiarto, A., Harper, J.D., Cooks, R.G., Ouyang, Z.: Design and characterization of a multisource hand-held tandem mass spectrometer. Anal. Chem. 80, 7198-7205 (2008)

55. Gao, L., Cooks, R.G., Ouyang, Z.: Breaking the pumping speed barrier in mass spectrometry: discontinuous atmospheric pressure interface. Anal. Chem. 80, 4026-4032 (2008)

56. Xu, W., Charipar, N., Kirleis, M.A., Xia, Y., Ouyang, Z.: Study of discontinuous atmospheric pressure interfaces for mass spectrometry instrumentation development. Anal. Chem. 82, 6584-6592 (2010)

57. Huang, G., Xu, W., Visbal-Onufrak, M.A., Ouyang, Z., Cooks, R.G.: Direct analysis of melamine in complex matrices using a handheld mass spectrometer. Analyst. 135, 705-711 (2010)

58. Soparawalla, S., Tadjimukhamedov, F.K., Wiley, J.S., Ouyang, Z., Cooks, R.G.: In situ analysis of agrochemical residues on fruit using ambient ionization on a handheld mass spectrometer. Analyst. 136, 4392-4396 (2011)

59. Hansel, A., Jordan, A., Holzinger, R., Prazeller, P., Vogel, W., Lindinger, W.: Proton transfer reaction mass spectrometry: on-line trace gas analysis at the ppb level. Int. J. Mass Spectrom. Ion Processes. 149, 609-619 (1995)

60. Pachuta, S.J., Kenttamaa, H.I., Sack, T.M., Cerny, R.L., Tomer, K.B., Gross, M.L., Pachuta, R.R., Cooks, R.G.: Excitation and dissociation of isolated ions derived from polycyclic aromatic hydrocarbons. J. Am. Chem. Soc. 110, 657-665 (1988) 